\title{
Morphometric analysis of the coracoid process and glenoid width: a 3D-CT study
}

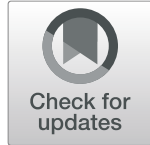

\author{
Yaofei Jia ${ }^{1,2,3}, \mathrm{Na} \mathrm{He}^{3}$, Jiaxin Liu ${ }^{1,2}$, Guangrui Zhang ${ }^{1,2}$, Jianping Zhou ${ }^{1,2}$, Ding Wu ${ }^{1,2}$, Baomin Wei $^{3}$ \\ and Xiangdong Yun ${ }^{1,2^{*}}$ (D)
}

\begin{abstract}
Background: Data regarding the parameters of the coracoid process and glenoid width are insufficient, and information on gender, age, and ethnic differences in the parameters appear lacking in the Chinese population. This study aimed to investigate the morphometric parameters in the coracoid process and glenoid width.

Methods: Using our institution's electronic database, we selected 84 patients (55 males and 29 females) who underwent a shoulder computed tomography (CT) scan from January 2017 to May 2018 in this study. Mimics19.0 software was used for three-dimensional (3D) reconstruction of CT and to measure the morphometric parameters of the coracoid process and glenoid width. Subgroup analyses stratified by gender and age were conducted and the parameters were compared with previously published reports. All data were statistically analysed by SPSS23.0 Statistical Package.
\end{abstract}

Results: A positive and significant relationship between the coracoid process and the glenoid width $(R>0.758, P<$ 0.01) was found. The midpoint width represents 52\% (41-62\%) of the glenoid width; the midpoint height, $40 \%$ (31$53 \%)$ of the glenoid width. Significant differences in all parameters between males and females were noted $(P<0.05)$. No significant differences among the age groups were observed $(P>0.05)$, whereas significant differences in almost all parameters between the ethnic groups were observed $(P<0.05)$.

Conclusion: Our results could supplement the information in the shoulder joint database with morphometric parameters and provide a reference for theoretical research on coracoid osteotomy, which may in turn help surgeons in the evaluation of coracoid process transfer.

Keywords: Coracoid process, Glenoid width, 3D-CT, Morphometric parameters, Relationship

\section{Introduction}

As the most mobile and unstable joint in the human body, the glenohumeral joint is the most commonly dislocated joint. Patients with a significant glenoid bone loss remain to have a high failure rate after Bankart repair [1-3]. Numerous investigations have reported on glenoid reconstruction procedures that utilise the coracoid process, iliac crest [4], or femoral head distal tibia autologous bone, as well as distal tibial allografts [5-8]. Coracoid transfer to the anterior glenoid (Latarjet

\footnotetext{
*Correspondence: yunxiangdong_vip@163.com

'Department of Orthopedics, Lanzhou University Second Hospital, No. 82

Cuiyingmen, Chengguan District, Lanzhou, Gansu, China

${ }^{2}$ Key Laboratory of Orthopedics of Gansu Province, No. 82 Cuiyingmen,

Chengguan District, Lanzhou 730030, Gansu, China

Full list of author information is available at the end of the article
}

procedure) is the most common reconstruction procedure [9-11].

The Latarjet procedure, which is also known as the coracoid process transfer, was first described in 1954 and used "bone block" of the coracoid for anteroinferior shoulder instability [12]. The coracoid increases the surface area of the glenoid, and the conjoint tendon and intact subscapularis provide the "sling effect" [13, 14], which plays an especially important role in mid- to endrange shoulder abduction [15]. Whether a coracoid graft (Latarjet procedure) could sufficiently restore glenoid bone loss remains to be clearly established. In 2002, Edwards et al. [16] reported that in patients with bone loss of $>33 \%$ of the glenoid width, the coracoid bone could be insufficient to reconstruct the glenoid. In 2005, Chen et al. [17] demonstrated that for glenoid bone defects >

(c) The Author(s). 2020 Open Access This article is distributed under the terms of the Creative Commons Attribution 4.0 International License (http://creativecommons.org/licenses/by/4.0/), which permits unrestricted use, distribution, and 
20-33\%, the Latarjet, Bristow, or other bone-grafting procedures could be used to reconstruct the glenoid. In 2011, Abboud et al. [18] reported that for glenoid bone loss > 21-50\%, the Latarjet procedure could be employed to restore the glenoid.

In addition, reverse total shoulder arthroplasty (RTSA) has been successful in improving function and pain in patients with severe rotator cuff arthropathy and glenohumeral arthritis [19, 20]. Glenoid component loosening is the dominant cause of failure in RTSA [21]. Importantly, optimal glenoid component design and ability to reconstruct the normal glenohumeral anatomy contributes to improved stability of glenoid component fixation and fewer complications [22, 23]. Therefore, the accurate anatomic data of glenoid bone is crucial for new glenoid component design and necessary for the pre-operative planning of RTSA.

Previous investigations reported the bony dimensions of the coracoid process and glenoid width using computed tomography (CT) scan data; however, the number of studies that define the morphometric parameters of the coracoid process and glenoid width based on 3D-CT reconstruction in the Chinese population is limited. Thus, the purpose of this study was to evaluate the morphometric parameters in the coracoid process and glenoid width using three-dimensional computed tomography (3D-CT) reconstruction and to determine whether a significant difference in the coracoid process and glenoid width dimensions based on sex, age, and ethnicity exists.

\section{Materials and methods}

\section{Study participants}

Using the electronic database of the Lanzhou University Second Hospital, 124 patients who underwent CT scan of the shoulder from January 2017 to May 2018 were selected. Inclusion criteria were as follows: age 20-60 years old and Constant-Murley score > 90; all patients signed written informed consent. The exclusion criteria were as follows: previous scapular or humeral fracture, previous shoulder surgery, periarthritis of the shoulder, tumours around the shoulder, and shoulder joint instability. After applying the exclusion criteria, 84 patients (55 males and 29 females) were included in this study. The study protocol was performed in accordance with the Declaration of Helsinki and was approved by the institutional review board of the Lanzhou University Second Hospital.

\section{Parameters of the measurement}

Mimics19.0 software (Materialise, Leuven, Belgium) was used to perform the $3 \mathrm{D}$ reconstruction of $\mathrm{CT}$ and to measure the anatomical parameters of the coracoid process and the glenoid width. All parameters were performed by two researchers who were blinded to each other's data, and the data from the two researchers were averaged and recorded. The following bony dimensions of the coracoid process and the glenoid width were measured for each patient: coracoid length (distance from tip to base), coracoid tip height, coracoid tip width, distance from the coracoid tip or base to the coracoid midpoint (hereafter termed "midpoint"), midpoint height, midpoint width, and maximum anteroposterior diameter of the glenoid (glenoid width) (Fig. 1).

\section{Statistical analysis}

All data were statistically analysed using SPSS version 23.0 (IBM Corporation, New York, NY, USA) and expressed as mean \pm standard deviation (SD). The parameters were compared between males and females using independent samples $t$ test. A comparison of all parameters among four age groups was analysed using one-way analysis of variance. Correlations among all parameters were evaluated by Pearson correlation analysis. All parameters were compared with previously published reports using one-sample $t$ test. All statistical tests were two-tailed, and a $P$ value $<0.05$ was considered statistically significant.

\section{Results}

The mean age of all patients was $41.63( \pm 12.06)$ years. The patients were categorised by age as follows: $20-30$, $31-40,41-50$, and 51-60 years old. The bony dimensions (Fig. 1) were measured. The anatomic dimensions of the coracoid process and glenoid width are presented in Table 1. The ratio between the midpoint width, the midpoint height, and the glenoid width was calculated. Results showed that the midpoint width represented 41$62 \%$ of the glenoid width (52\% on average) and the midpoint height represented $31-53 \%$ of the glenoid width (40\% on average).

As shown in Table 2, differences in all parameters between males and females were significant $(P<0.05)$, with the male parameters being consistently greater. By contrast, no significant differences in all parameters among the four age groups were found $(P>0.05)$ (Table 3$)$.

The Pearson correlation analysis and scatter plots are presented in Table 4 and Fig. 2. Data analysis revealed a significant positive correlation between the coracoid process and the glenoid width $(R>0.758, P<0.01)$, for example, we observed a positive $(R=0.758)$ and statistically significant $(P<0.01)$ correlation between the midpoint width and the glenoid width, and a positive $(R=0.766)$ and statistically significant $(P<0.01)$ correlation between the midpoint height and the glenoid width was also noted.

Furthermore, all parameters between the Chinese population and the populations from various countries and ethnic groups were compared (Table 5). Generally, Asians have shorter dimensions of the coracoid process 

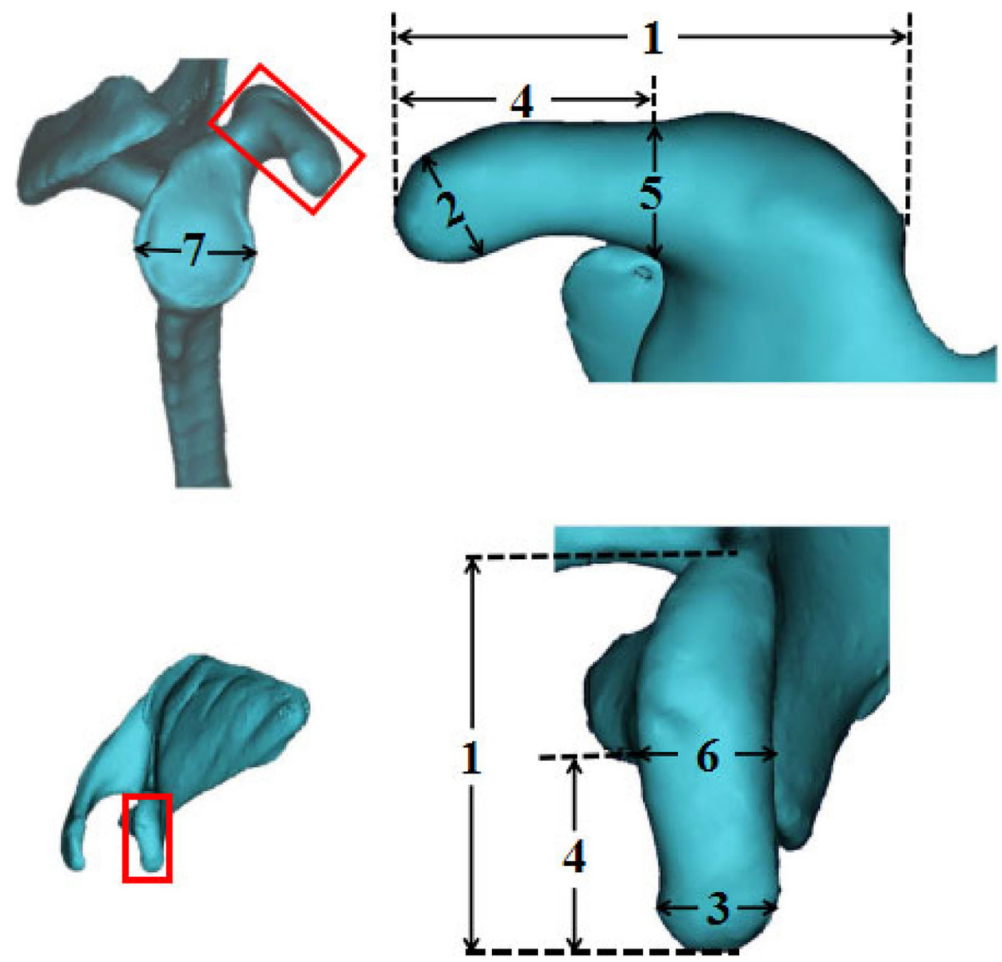

Fig. 1 The coracoid process and glenoid cavity measurements. 1, coracoid length (distance from tip to base); 2, coracoid tip height; 3, coracoid tip width; 4, distance from the coracoid tip or base to the coracoid midpoint; 5, midpoint height; 6 , midpoint width; 7, maximum anteroposterior diameter of the glenoid (glenoid width)

and glenoid width than Caucasians and Africans $(P<$ 0.05). Moreover, the coracoid length $(37.94 \pm 4.30 \mathrm{~mm})$ and tip width $(11.63 \pm 2.12 \mathrm{~mm})$ in the Malaysian population were found to be the smallest $(P<0.05)$. The distance from the coracoid tip/base to the midpoint was greater in the Mongolian Chinese $(24.75 \pm 7.23 \mathrm{~mm})$ than in the American population $(22.8 \pm 2.1 \mathrm{~mm})$.

\section{Discussion}

Morphometric evaluation of the coracoid process, which is a potential mediator and key structure of shoulder pathology and surgery, has been performed by various

Table 1 Anatomic dimensions of the coracoid process and glenoid width

\begin{tabular}{llll}
\hline Variable $(\mathrm{mm})$ & Mean \pm SD & \multicolumn{2}{l}{ Range $(\mathrm{mm})$} \\
\cline { 3 - 4 } & & Min & Max \\
\hline Coracoid length & $41.60 \pm 4.04$ & 29.6 & 49.51 \\
Tip height & $9.05 \pm 1.83$ & 5.62 & 14.26 \\
Tip width & $13.09 \pm 2.06$ & 8.46 & 19.65 \\
Tip/base to midpoint & $20.80 \pm 2.02$ & 14.80 & 24.75 \\
Midpoint height & $11.12 \pm 1.97$ & 7.40 & 15.77 \\
Midpoint width & $14.59 \pm 2.07$ & 10.54 & 18.28 \\
Glenoid width & $27.86 \pm 2.69$ & 21.68 & 33.46 \\
\hline
\end{tabular}

authors in different populations using dry osteology, fresh cadaver, or 3D-CT reconstruction. However, data on the evaluation of the coracoid process morphology using CT scans in the Chinese population are extremely few. Moreover, data regarding the relationship between the coracoid process and the glenoid width are insufficient, and information on sex, age, and ethnic differences in the morphometry of the coracoid process appears lacking.

\section{The relationship between the coracoid process and the glenoid width}

In our study, a positive and significant relationship between the coracoid process and the glenoid width was found $(R>0.758, P<0.01)$, which is consistent with a previous study in an Indian population $(R>0.631)$ [26]. The average midpoint width/glenoid width ratio was $52 \%$ (range 41-62\%), and the average midpoint height/glenoid width ratio was $40 \%$ (range 31-53\%). This finding could be helpful for surgeons in restoring glenoid bone loss with a coracoid bone. In 2012, one study [36] reported that the midpoint width/glenoid width ratio represented 54\% (43$70 \%)$ and the midpoint height/glenoid width ratio represented 31\% (25-37\%) of the glenoid width; moreover, a significant positive correlation between the coracoid tip width and the glenoid width was found $(R=0.677, P<$ 0.01 ), thereby strengthening the validity of the ratio in our 
Table 2 Comparison of the coracoid process and glenoid width according to gender

\begin{tabular}{|c|c|c|c|c|}
\hline Variable (mm) & $\begin{array}{l}\text { Male }(n=55) \\
\text { Mean } \pm \text { SD }\end{array}$ & $\begin{array}{l}\text { Female }(n=29) \\
\text { Mean } \pm S D\end{array}$ & $P$ value* & $95 \% \mathrm{Cl}$ \\
\hline Coracoid length & $43.56 \pm 3.20$ & $37.90 \pm 2.65$ & 0.000 & $4.27-7.04$ \\
\hline Tip height & $9.82 \pm 1.55$ & $7.58 \pm 1.35$ & 0.000 & $1.56-2.92$ \\
\hline Tip width & $13.97 \pm 1.81$ & $11.43 \pm 1.39$ & 0.000 & $1.77-3.30$ \\
\hline Tip/base to midpoint & $21.78 \pm 1.60$ & $18.95 \pm 1.32$ & 0.000 & $2.14-3.52$ \\
\hline Midpoint height & $12.03 \pm 1.72$ & $9.41 \pm 1.08$ & 0.000 & $2.00-3.23$ \\
\hline Midpoint width & $15.54 \pm 1.73$ & $12.79 \pm 1.35$ & 0.000 & $2.02-3.49$ \\
\hline Glenoid width & $29.09 \pm 2.27$ & $25.52 \pm 1.72$ & 0.000 & $2.61-4.53$ \\
\hline
\end{tabular}

${ }^{*} P<0.05$ indicates statistical significance

results. In 2002, Edwards et al. [16] reported that in patients with bone loss of $>33 \%$ of the glenoid width, the coracoid bone could be insufficient for glenoid reconstruction. In addition, some authors recommended removing the coracoid cortical surface to increase the healing rate of the glenoid neck. Consequently, glenoid reconstruction was possible in most people with glenoid bone loss in our study.

\section{Gender differences in morphometric measurements of the coracoid process and the glenoid width}

The coracoid morphological parameters stratified by gender showed that all parameters were significantly greater in males than in females, which is in agreement with the findings of previous studies [24, 29, 31, 33, 38]. Conversely, Imma et al. [27] found significant sexrelated differences in the measurements except for the base height, tip length, and midpoint width. This conflicting result could be because the study was not stratified by ethnicities; moreover, the discrepancy could also be explained by two possible reasons: small sample size (15 pairs of shoulder joints) and a mixture of three ethnicities (Malay, Chinese, and Indian subjects).

\section{Age differences in morphometric measurements of the coracoid process and the glenoid width}

To the best of our knowledge, only one study [28] reported on the morphology of the coracoid process and glenoid width based on age, which demonstrated significant differences in all measurements according to age ( $P$ $<0.001)$. The discrepancy between the previous study's findings and our results could be attributed to the mixture of two ethnicities (i.e. Caucasians and AfricanAmericans) in the former, and the measurements of the specimens vary (i.e. dry osteology vs. CT scan). Specifically, to eliminate the influence of confounding factors with increasing age, we excluded patients with the previous scapular or humeral fracture, previous shoulder surgery, periarthritis of the shoulder, tumours around the shoulder, and shoulder joint instability. Moreover, all measurements were performed by two researchers who were blinded to patients' age, thereby minimising the potential observer bias.

\section{Ethnic differences in morphometric measurements of the coracoid process and the glenoid width}

Parameters of the coracoid process and glenoid width in previously published reports vary, and a comparison of our parameters with those of previous studies is difficult as the studies have different ways of measuring the specimens (i.e. using dry bone, fresh cadaveric bone, or CT scan). For example, some previous studies defined the coracoid tip length as the distance from the coracoid tip to the "elbow" or "knee" of the coracoid [30, 34, 38]; therefore, the coracoid tip length was excluded in the

Table 3 Comparison of the coracoid process and glenoid width according to age

\begin{tabular}{|c|c|c|c|c|c|c|c|c|c|c|}
\hline \multirow[t]{2}{*}{ Variable (mm) } & \multicolumn{2}{|c|}{$20-30(n=21)$} & \multicolumn{2}{|c|}{$31-40(n=14)$} & \multicolumn{2}{|c|}{$41-50(n=24)$} & \multicolumn{2}{|c|}{$51-60(n=25)$} & \multirow{2}{*}{$\begin{array}{l}F \\
\text { value }\end{array}$} & \multirow{2}{*}{$\begin{array}{l}P \\
\text { value }\end{array}$} \\
\hline & Mean \pm SD & $95 \% \mathrm{Cl}$ & Mean \pm SD & $95 \% \mathrm{Cl}$ & Mean \pm SD & $95 \% \mathrm{Cl}$ & Mean \pm SD & $95 \% \mathrm{Cl}$ & & \\
\hline Coracoid length & $41.96 \pm 3.91$ & $40.18-43.74$ & $40.92 \pm 4.40$ & $38.38-43.46$ & $41.33 \pm 3.47$ & $39.86-42.79$ & $41.96 \pm 4.60$ & $40.06-43.86$ & 0.281 & 0.839 \\
\hline Tip height & $9.08 \pm 1.72$ & $8.30-9.86$ & $8.52 \pm 1.99$ & $7.37-9.67$ & $8.76 \pm 1.39$ & $8.17-9.35$ & $9.60 \pm 2.12$ & $8.73-10.48$ & 1.373 & 0.257 \\
\hline Tip width & $12.90 \pm 1.69$ & $12.14-13.67$ & $12.99 \pm 2.38$ & $11.61-14.36$ & $12.75 \pm 1.88$ & $11.95-13.54$ & $13.64 \pm 2.32$ & $12.69-14.60$ & 0.886 & 0.452 \\
\hline Tip/base to midpoint & $20.98 \pm 1.95$ & $20.09-21.87$ & $20.46 \pm 2.20$ & $19.19-21.73$ & $20.67 \pm 1.74$ & $19.93-21.40$ & $20.98 \pm 2.30$ & 20.03-21.93 & 0.281 & 0.839 \\
\hline Midpoint height & $11.64 \pm 2.22$ & $10.63-12.65$ & $10.55 \pm 1.89$ & $9.46-11.64$ & $10.89 \pm 1.62$ & $10.21-11.58$ & $11.23 \pm 2.10$ & $10.36-12.10$ & 1.002 & 0.396 \\
\hline Midpoint width & $14.40 \pm 2.03$ & $13.48-15.33$ & $14.15 \pm 2.14$ & $12.91-15.39$ & $14.52 \pm 1.99$ & $13.67-15.36$ & $15.07 \pm 2.17$ & $14.17-15.96$ & 0.717 & 0.545 \\
\hline Glenoid width & $27.67 \pm 2.90$ & $26.35-29.00$ & $27.30 \pm 2.43$ & $25.90-28.71$ & $27.82 \pm 2.52$ & $26.75-28.88$ & $28.36 \pm 2.88$ & 27.17-29.55 & 0.516 & 0.672 \\
\hline
\end{tabular}


Table 4 Pearson correlation analysis between the dimensions of the coracoid process and glenoid width

\begin{tabular}{llllllll}
\hline & Coracoid length & Tip height & Tip width & Tip/base to midpoint & Midpoint height & Midpoint width & Glenoid width \\
\hline Coracoid length & 1 & $0.737^{* *}$ & $0.677^{* *}$ & $1.000^{* *}$ & $0.645^{* *}$ & $0.707^{* *}$ & $0.772^{* *}$ \\
Tip height & $0.737^{* *}$ & 1 & $0.820^{* *}$ & $0.737^{* *}$ & $0.813^{* *}$ & $0.788^{* *}$ & $0.813^{* *}$ \\
Tip width & $0.677^{* *}$ & $0.820^{* *}$ & 1 & $0.677^{* *}$ & $0.746^{* *}$ & $0.846^{* *}$ & $0.758^{* *}$ \\
Tip/base to midpoint & $1.000^{* *}$ & $0.737^{* *}$ & $0.677^{* *}$ & 1 & $0.645^{* *}$ & $0.707^{* *}$ & $0.772^{* *}$ \\
Midpoint height & $0.645^{* *}$ & $0.813^{* *}$ & $0.746^{* *}$ & $0.645^{* *}$ & 1 & $0.750^{* *}$ & $0.766^{* *}$ \\
Midpoint width & $0.707^{* *}$ & $0.788^{* *}$ & $0.846^{* *}$ & $0.707^{* *}$ & $0.750^{* *}$ & 1 & $0.758^{* *}$ \\
Glenoid width & $0.772^{* *}$ & $0.813^{* *}$ & $0.758^{* *}$ & $0.772^{* *}$ & $0.766^{* *}$ & $0.758^{* *}$ & 1 \\
\hline
\end{tabular}

${ }^{* *} P<0.01$ indicates statistical significance

comparison between the coracoid process and glenoid width among different ethnic populations. Generally, Asians have smaller coracoid process and glenoid width dimensions than Caucasians and Africans $(P<0.05)$, except for the distance from the coracoid tip/base to the coracoid midpoint among Mongolian Chinese [25]; the difference could be attributed to genetic as well as environmental influence, dietary habits, and lifestyle. Interestingly, no significant difference exists about glenoid width between the present study and a previous study [37] in Switzerland cadavers, which could be explained by the study focusing on body donors with an average age of 84 years (range 60-98 years), leading to degree of glenoid wear, and small sample sizes (18 cadavers).
This study has some inherent limitations. Because of the tortuous morphology on CT scans, identifying the bony landmarks was difficult. Although the measurements were performed by two researchers blinded to each other's data, some errors were inevitable. Moreover, a previous study [25] reported that taller patients have a shorter coracoid height, and performing the congruent-arc Latarjet for these patients appears not a reasonable option as there is not enough space for the use of two $3.5-\mathrm{mm}$ screws. However, we did not analyse the patient's height. Thus, further investigations should include the evaluation of the patient's height when performing the Latarjet technique in patients with glenoid bone loss.

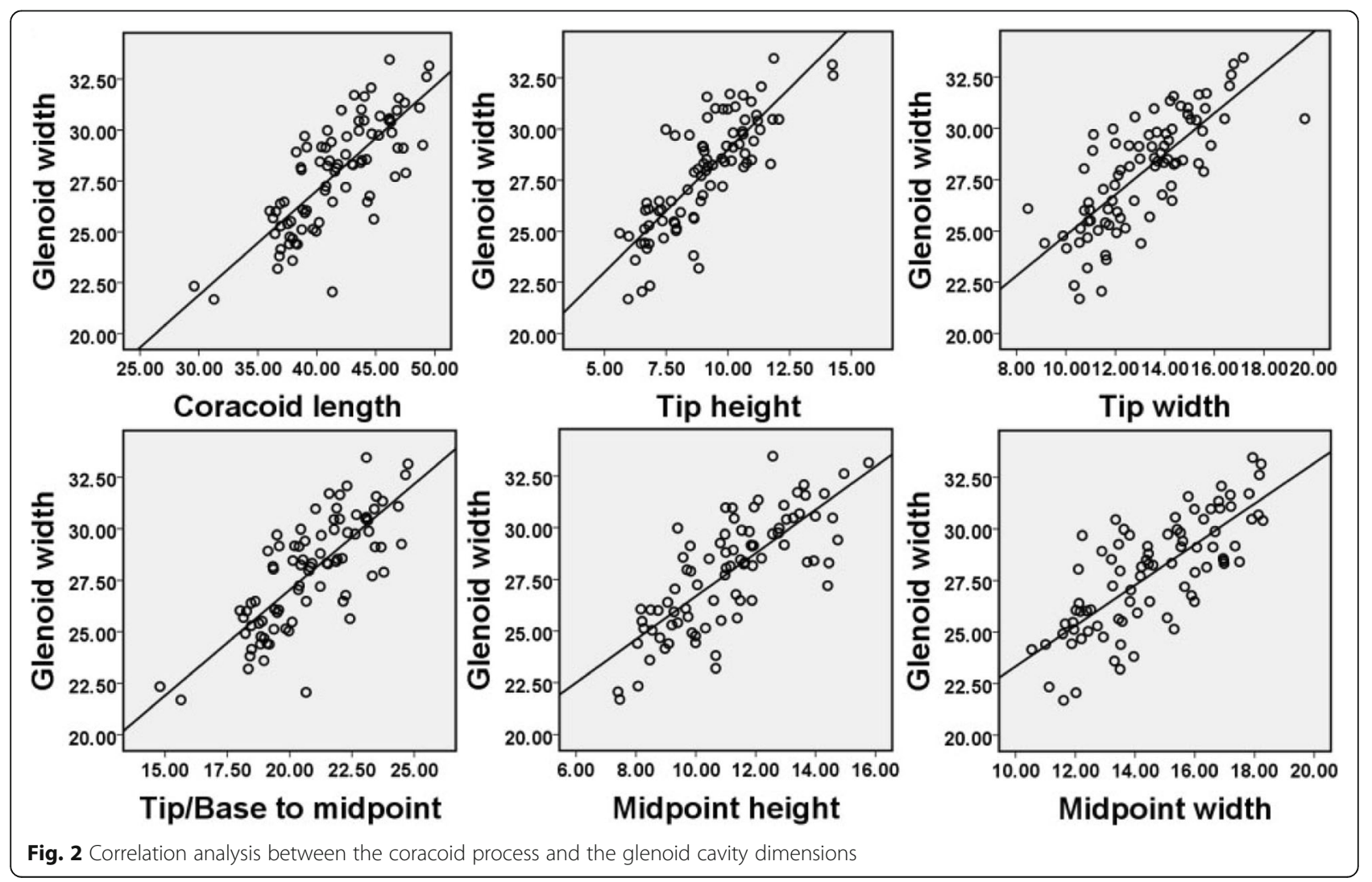


Table 5 Measurements of coracoid process and glenoid width in different ethnic populations

\begin{tabular}{|c|c|c|c|c|c|c|c|c|}
\hline Populations & $\begin{array}{l}\text { Coracoid length } \\
(\mathrm{mm})\end{array}$ & $\begin{array}{l}\text { Tip height } \\
(\mathrm{mm})\end{array}$ & $\begin{array}{l}\text { Tip width } \\
(\mathrm{mm})\end{array}$ & $\begin{array}{l}\text { Tip/base to } \\
\text { midpoint } \\
\text { (mm) }\end{array}$ & $\begin{array}{l}\text { Midpoint } \\
\text { height (mm) }\end{array}$ & $\begin{array}{l}\text { Midpoint width } \\
(\mathrm{mm})\end{array}$ & $\begin{array}{l}\text { Glenoid width } \\
(\mathrm{mm})\end{array}$ & References \\
\hline \multicolumn{9}{|l|}{ Asians } \\
\hline Chinese & $41.60 \pm 4.04$ & $9.05 \pm 1.83$ & $13.09 \pm 2.06$ & $20.80 \pm 2.02$ & $11.12 \pm 1.97$ & $14.59 \pm 2.07$ & $27.86 \pm 2.69$ & Present study \\
\hline Chinese & $42.47 \pm 1.02$ & $9.08 \pm 0.58$ & $13.17 \pm 0.51$ & - & - & - & - & [24] \\
\hline Chinese & $42.10 \pm 2.31$ & $9.10 \pm 1.75$ & $13.61 \pm 2.00^{*}$ & $24.75 \pm 7.23^{*}$ & $11.61 \pm 1.98^{*}$ & $15.29 \pm 1.70^{*}$ & - & [25] \\
\hline Indian & $43.32 \pm 1.54^{*}$ & $11.47 \pm 0.62^{*}$ & $13.63 \pm 1.09^{*}$ & - & - & - & - & [24] \\
\hline Indian & $40.45 \pm 4.43$ & - & - & - & $8.54 \pm 1.7^{*}$ & $14.16 \pm 2.39$ & $23.96 \pm 3.22^{*}$ & [26] \\
\hline Myanmarese & $39.19 \pm 1.38^{*}$ & $8.58 \pm 1.03$ & $13.02 \pm 1.32$ & - & - & & - & [24] \\
\hline Malaysian & $37.94 \pm 4.30^{*}$ & $9.24 \pm 1.16$ & $11.63 \pm 2.12^{*}$ & - & - & $13.84 \pm 1.76^{*}$ & - & [27] \\
\hline \multicolumn{9}{|l|}{ Caucasians } \\
\hline American & $46.0 \pm 3.7^{*}$ & $9.2 \pm 1.2$ & $15.9 \pm 1.9^{*}$ & - & - & - & $29.2 \pm 2.5^{*}$ & {$[28]$} \\
\hline American & $45.8 \pm 4.2^{*}$ & - & - & - & - & - & - & [29] \\
\hline American & - & $10.4 \pm 1.4^{*}$ & $15.9 \pm 2.2^{*}$ & - & - & - & - & [30] \\
\hline American & $45.0 \pm 3.8^{*}$ & - & - & - & - & - & - & [31] \\
\hline American & $45.6 \pm 4.2^{*}$ & $11.5 \pm 0.9^{*}$ & $18.3 \pm 1.8^{*}$ & $22.8 \pm 2.1^{*}$ & $13.5 \pm 1.6^{*}$ & $16.1 \pm 2.3^{*}$ & - & [32] \\
\hline German & $43.1 \pm 2.2^{*}$ & $8.2 \pm 1^{*}$ & $13.6 \pm 2.1^{*}$ & - & - & - & - & [33] \\
\hline Canadian & - & $10.5 \pm 1.7^{*}$ & $15.0 \pm 2.2^{*}$ & - & - & - & - & [34] \\
\hline Brazilian & $42.6 \pm 2.6$ & $14.9 \pm 1.2^{*}$ & $21.1 \pm 2.0^{*}$ & - & - & - & - & [35] \\
\hline Brazilian & - & - & - & - & $8.37 \pm 0.93^{*}$ & $14.51 \pm 1.90$ & $26.38 \pm 2.69^{*}$ & [36] \\
\hline Switzerland & - & - & - & - & - & - & $27.8 \pm 3.1$ & [37] \\
\hline \multicolumn{9}{|l|}{ Africans } \\
\hline African-American & $44.4 \pm 4.2^{*}$ & $9.4 \pm 1.4$ & $15.3 \pm 2.1$ & - & - & - & $28.1 \pm 3.0$ & [28] \\
\hline African-American & $43.7 \pm 3.8^{*}$ & - & - & - & - & - & & [29] \\
\hline
\end{tabular}

${ }^{*} P<0.05$ indicates statistical significance; - Represents no parameters in the study

\section{Conclusions}

Our study demonstrated a positive and significant relationship between the coracoid process and the glenoid width, and a significant difference in the coracoid process and glenoid width dimensions based on sex and ethnicity was identified. These findings could supplement the data in the shoulder joint database with the anatomical parameters of the Chinese population, which may in turn help surgeons in evaluating the need for coracoid osteotomy and transfer during preoperative planning and intraoperative decision-making. Nevertheless, further studies with a larger sample size are required to validate our findings.

\section{Abbreviations}

3D: Three-dimensional; CT: Computed tomography; RTSA: Reverse total shoulder arthroplasty; SD: Standard deviation

\section{Acknowledgements}

The authors thank Professor Jianli Liu for kindly allowing us to use the electronic database of the Lanzhou University Second Hospital. They also thank Dr Liping An for assistance with the laboratory measurements. We would like to thank Editage (www.editage.com) for English language editing.
Authors' contributions

XDY and YFJ contributed to the conception or design of the work. JXL and GRZ contributed to drafting the work and revising it critically for important intellectual content. JPZ and BMW contributed to interpret and analyse data for the work. NH and YFJ wrote the first draft of the manuscript and all authors contributed to the review, approval of the final manuscript, and agreed to be accountable for all aspects of the work.

\section{Funding}

This work was supported by the doctor fund of Lanzhou University Second Hospital (grant number 81560361).

Availability of data and materials

Upon request, raw data can be provided.

Ethics approval and consent to participate

The study was approved by the institutional review board of the Lanzhou University Second Hospital, and the written informed consent of the participants was obtained.

\section{Consent for publication}

Consent to publish from the participants who took part in this study was obtained.

\section{Competing interests}

The authors declare that they have no competing interests.

\section{Author details}

${ }^{1}$ Department of Orthopedics, Lanzhou University Second Hospital, No. 82 Cuiyingmen, Chengguan District, Lanzhou, Gansu, China. ${ }^{2}$ Key Laboratory of 
Orthopedics of Gansu Province, No. 82 Cuiyingmen, Chengguan District, Lanzhou 730030, Gansu, China. ${ }^{3}$ People's Hospital of Changwu County, Xianyang 713600, Shaanxi, China.

Received: 9 January 2020 Accepted: 13 February 2020

Published online: 24 February 2020

\section{References}

1. Mologne TS, Provencher MT, Menzel KA, Vachon TA, Dewing CB. Arthroscopic stabilization in patients with an inverted pear glenoid: results in patients with bone loss of the anterior glenoid. Am J Sports Med. 2007; 35(8):1276-83

2. Park JY, Lee SJ, Lhee SH, Lee SH. Follow-up computed tomography arthrographic evaluation of bony Bankart lesions after arthroscopic repair. Arthroscopy. 2012;28(4):465-73.

3. Sugaya H, Moriishi J, Kanisawa I, Tsuchiya A. Arthroscopic osseous Bankart repair for chronic recurrent traumatic anterior glenohumeral instability. J Bone Joint Surg Am. 2005;87(8):1752-60.

4. Warner JJ, Gill TJ, O'Hollerhan JD, Pathare N, Millett PJ. Anatomical glenoid reconstruction for recurrent anterior glenohumeral instability with glenoid deficiency using an autogenous tricortical iliac crest bone graft. Am J Sports Med. 2006;34(2):205-12

5. Bhatia S, Van Thiel GS, Gupta D, Ghodadra N, Cole BJ, Bach BR, Shewman E, Wang VM, Romeo AA, Verma NN. Comparison of glenohumeral contact pressures and contact areas after glenoid reconstruction with latarjet or distal tibial osteochondral allografts. Am J Sports Med. 2013:41(8).

6. Hutchinson JW, Neumann L, Wallace WA. Bone buttress operation for recurrent anterior shoulder dislocation in epilepsy. J Bone Joint Surg Br. 1995;77(6):928-32.

7. Provencher MT, Bhatia S, Ghodadra NS, Grumet RC, Bach BR Jr, Dewing CB, LeClere L, Romeo AA. Recurrent shoulder instability: current concepts for evaluation and management of glenoid bone loss. J Bone Joint Surg Am. 2010;92(Suppl 2):133-51.

8. Provencher MT, Ghodadra N, LeClere L, Solomon DJ, Romeo AA. Anatomic osteochondral glenoid reconstruction for recurrent glenohumeral instability with glenoid deficiency using a distal tibia allograft. Arthroscopy. 2009;25(4): 446-52.

9. Boons HW, Giles JW, Elkinson I, Johnson JA, Athwal GS. Classic versus congruent coracoid positioning during the Latarjet procedure: an in vitro biomechanical comparison. Arthroscopy. 2013;29(2):309-16.

10. Burkhart SS, De Beer JF, Barth JR, Cresswell T, Roberts C, Richards DP. Results of modified Latarjet reconstruction in patients with anteroinferior instability and significant bone loss. Arthroscopy. 2007;23(10):1033-41.

11. de Beer JF, Roberts C. Glenoid bone defects-open latarjet with congruent arc modification. Orthop Clin North Am. 2010;41(3):407-15.

12. Latarjet M. Treatment of recurrent dislocation of the shoulder. Lyon Chirurgical. 1954;49(8):994-7.

13. Giles JW, Boons HW, Elkinson I, Faber KJ, Ferreira LM, Johnson JA, Athwal GS. Does the dynamic sling effect of the Latarjet procedure improve shoulder stability? A biomechanical evaluation. J Shoulder Elbow Surg. 2013; 22(6):821-7.

14. Wellmann $\mathrm{M}$, de Ferrari $\mathrm{H}$, Smith $\mathrm{T}$, Petersen $\mathrm{W}$, Siebert $\mathrm{CH}$, Agneskirchner JD, Hurschler C. Biomechanical investigation of the stabilization principle of the Latarjet procedure. Arch Orthop Trauma Surg. 2012;132(3):377-86.

15. Yamamoto N, Muraki T, An KN, Sperling JW, Cofield RH, Itoi E, Walch G, Steinmann SP. The stabilizing mechanism of the Latarjet procedure: a cadaveric study. J Bone Joint Surg Am. 2013;95(15):1390-7.

16. Edwards $T B$, Walch $\mathrm{G}$. The latarjet procedure for recurrent anterior shoulder instability: Rationale and technique *. Oper Tech Sports Med. 2002;10(1):25-32.

17. Chen AL, Hunt SA, Hawkins RJ, Zuckerman JD. Management of bone loss associated with recurrent anterior glenohumeral instability. Am J Sports Med. 2005;33(6):912-25.

18. Abboud JA, Armstrong AD. Management of anterior shoulder instability: ask the experts. J Shoulder Elbow Surg. 2011;20(2):173-82.

19. Dezfuli B, King JJ, Farmer KW, Struk AM, Wright TW. Outcomes of reverse total shoulder arthroplasty as primary versus revision procedure for proximal humerus fractures. J Shoulder Elbow Surg. 2016;25(7):1133-7.

20. Ji JH, Shafi M, Jeong JJ, Ha JY. Reverse total shoulder arthroplasty in the treatment of chronic anterior fracture dislocation complicated by a chronic full thickness retracted rotator cuff tear in an elderly patient. J Orthop Sci. 2016;21(2):237-40.
21. Hopkins AR, Hansen UN, Bull AM, Emery R, Amis AA. Fixation of the reversed shoulder prosthesis. J Shoulder Elbow Surg. 2008;17(6):974-80

22. Harman M, Frankle M, Vasey M, Banks S. Initial glenoid component fixation in "reverse" total shoulder arthroplasty: a biomechanical evaluation. J Shoulder Elbow Surg. 2005;14(1 Suppl S):162 s-7 s.

23. Virani NA, Harman M, Li K, Levy J, Pupello DR, Frankle MA. In vitro and finite element analysis of glenoid bone/baseplate interaction in the reverse shoulder design. J Shoulder Elbow Surg. 2008;17(3):509-21.

24. Fathi M, Cheah PS, Ahmad U, Nasir MN, San AA, Abdul Rahim E, Hussin P, Mahmud R, Othman F. Anatomic Variation in Morphometry of Human Coracoid Process among Asian Population. Biomed Res Int. 2017;2017: 6307019.

25. Lian J, Dong L, Zhao Y, Sun J, Zhang W, Gao C. Anatomical study of the coracoid process in Mongolian male cadavers using the Latarjet procedure. Orthopaed Surg Res. 2016;11(1):126.

26. Kalra S, Thamke S, Khandelwal A, Khorwal G. Morphometric analysis and surgical anatomy of coracoid process and glenoid cavity. J Anat Soc India. 2016;65(2):114-7.

27. Imma II, Nizlan NM, Ezamin AR, Yusoff S, Shukur MH. Coracoid Process Morphology using 3D-CT Imaging in a Malaysian Population. Malays Orthop J. 2017;11(2):30-5

28. Knapik DM, Cumsky J, Tanenbaum JE, Voos JE, Gillespie RJ. Differences in Coracoid and Glenoid Dimensions Based on Sex, Race, and Age: Implications for Use of the Latarjet Technique in Glenoid Reconstruction. HSS J. 2018;14(3):238-44.

29. Rios CG, Arciero RA, Mazzocca AD. Anatomy of the clavicle and coracoid process for reconstruction of the coracoclavicular ligaments. Am J Sports Med. 2007:35(5):811-7.

30. Lo IK, Burkhart SS, Parten PM. Surgery about the coracoid: neurovascular structures at risk. Arthroscopy. 2004;20(6):591-5.

31. Coale RM, Hollister SJ, Dines JS, Allen AA, Bedi A. Anatomic considerations of transclavicular-transcoracoid drilling for coracoclavicular ligament reconstruction. J Shoulder Elbow Surg. 2013:22(1):137-44.

32. Dolan CM, Hariri S, Hart ND, McAdams TR. An anatomic study of the coracoid process as it relates to bone transfer procedures. J Shoulder Elbow Surg. 2011;20(3):497-501.

33. Salzmann GM, Paul J, Sandmann GH, Imhoff AB, Schottle PB. The coracoidal insertion of the coracoclavicular ligaments: an anatomic study. Am J Sports Med. 2008:36(12):2392-7.

34. Armitage MS, Elkinson I, Giles JW, Athwal GS. An anatomic, computed tomographic assessment of the coracoid process with special reference to the congruent-arc latarjet procedure. Arthroscopy. 2011;27(11):1485-9.

35. Terra BB, Ejnisman B, de Figueiredo EA, Cohen C, Monteiro GC, de Castro PA, Andreoli CV, Cohen M. Anatomic study of the coracoid process: safety margin and practical implications. Arthroscopy. 2013;29(1):25-30.

36. Bueno RS, Ikemoto RY, Nascimento LG, Almeida LH, Strose E, Murachovsky J. Correlation of coracoid thickness and glenoid width: an anatomic morphometric analysis. Am J Sports Med. 2012:40(7):1664-7.

37. Mathews S, Burkhard M, Serrano N, Link K, Häusler M, Frater N, Franke I, Bischofberger H, Buck FM, Gascho D. Glenoid morphology in light of anatomical and reverse total shoulder arthroplasty: a dissection- and 3D-CTbased study in male and female body donors. BMC Musculoskelet Disord. 2017;18(1):9.

38. Ljungquist KL, Butler RB, Griesser MJ, Bishop JY. Prediction of coracoid thickness using a glenoid width-based model: implications for bone reconstruction procedures in chronic anterior shoulder instability. J Shoulder Elbow Surg. 2012;21(6):815-21.

\section{Publisher's Note}

Springer Nature remains neutral with regard to jurisdictional claims in published maps and institutional affiliations. 